\title{
Classification of Diseases in General Medicine
}

\author{
Jose Luis Turabian* \\ Specialist in Family and Community Medicine, Spain
}

\section{ISSN: 2576-8816}

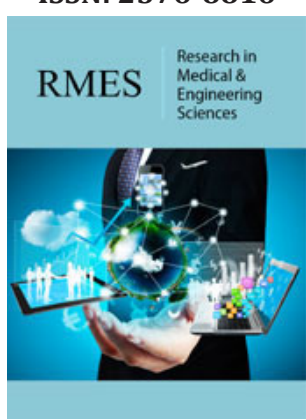

${ }^{*}$ Corresponding author: Jose Luis Turabian, Health Center Santa Maria de Benquerencia Toledo, Spain

Submission: 㭗 December 10, 2019

Published: 偨January 09, 2020

Volume 8 - Issue 4

How to cite this article: Jose Luis Turabian. Classification of Diseases in General Medicine. Res Med Eng Sci. 8(4). RMES.000691.2020.

DOI: 10.31031/RMES.2020.08.000691

Copyright@ Jose Luis Turabian, This article is distributed under the terms of the Creative Commons Attribution 4.0 International License, which permits unrestricted use and redistribution provided that the original author and source are credited.

\author{
Abstract \\ Keywords: General practice; Signs and symptoms; Classification
}

\section{Opinion}

To diagnose is to collect data to analyse and interpret them, which allows evaluating a certain condition. In medicine, therefore, a diagnosis seeks to reveal the manifestation of a disease from observing and analysing its symptoms. However, this observation of the signs of a disorder to recognize a disease is mediated by the theoretical framework in which we move [1].

Students learn, generally in a self-taught way, that there is a clinical method and that it consists of the scientific method applied to the individual care of the sick. That is, do a history of the disease that the patient tells, explore and perform complementary tests to collect objective data, build hypotheses about which organs are affected, and what disease causes it. However, it usually happens that, after being dazzled by the brightness of such a method in the hospital, when the doctor comes to work in general medicine, he begins to face the fact that, a certain part of the patients have diseases which cannot be fit in any classifications.

Not only were they precocious symptoms that did not meet the known criteria, or that seemed to give different manifestations from those seen in the hospital, but some of them were not sick from the doctor's point of view, but patients did consider it that way. At the time - much or little depending on the case - the young doctor is often discovering the truth: the training received until then was incomplete and biased. Its strong biologists dimension left out the psychological and social dimension with its expression in each patient.

In many cases, the diagnoses made correspond to "manifest diagnoses" or "partial or fragmentary diagnoses." [2]. Thus, sometimes, for example, diagnoses of anxiety, family and economic problems, headache, biliary colic due to biliary lithiasis, smoking and Carpal Tunnel Syndrome are made in the same patient. The patient has complementary tests that show his biliary lithiasis and Carpal Tunnel Syndrome, but surprisingly after the surgeon performs a cholecystectomy, abdominal pain follows. And after the traumatologist performs the Carpal Tunnel Syndrome intervention, they follow the same symptoms. What happened? We're not the diagnoses correct. The diagnoses were correct in their biological framework, but partial (no attempt was made to integrate them into a larger problem that encompassed them: for example, anxiety and psychosocial problems expressed with pain) [3]. Those diagnoses were also only the manifest aspect of the symptoms; The latent aspect was lacking, and consequently the "latent" diagnoses that are more integral and "true" in the sense of indicating better where to intervene to wait for better results (for example anxiety disorder, loneliness, poverty ...) (Figure 1).

So, when is a biological diagnosis made based on objective tests (how to diagnose Carpal Tunnel Syndrome based on symptoms and an Electromyogram) is it an error? No; it is not an error, but it can be how to choose the wrong path at a junction; we do not know where it will take us. Therefore, frequently the strictly biomedical intervention produces "bad results": the surgery was correct, but the symptoms persist.

Disease classifications are systems of categories to which morbid entries are assigned according to established criteria. The full range of conditions is included in a manageable 
number of categories, grouped to facilitate the mortality report [4]. But the classification is a "pseudo-knowledge", that is, it is really a form of de-knowledge, a quick and easy labelling whose function is to make unnecessary the effort required by a thought and perception more careful and ideographic. Placing a person within a previous system, requires less energy than knowing it by itself, since in the first case the only thing that is essential is the perception that category that allows you to identify it as belonging to a certain class, for example, Waiters, Swedes, schizophrenics, females, military, nurses, etc. What is underlined in the classifications is the category to which the person belongs, the category of which is a representative example, instead of underlining the person as such; it accentuates the similarities more than the differences, but surely each person would shout at us: "I am me, only me".

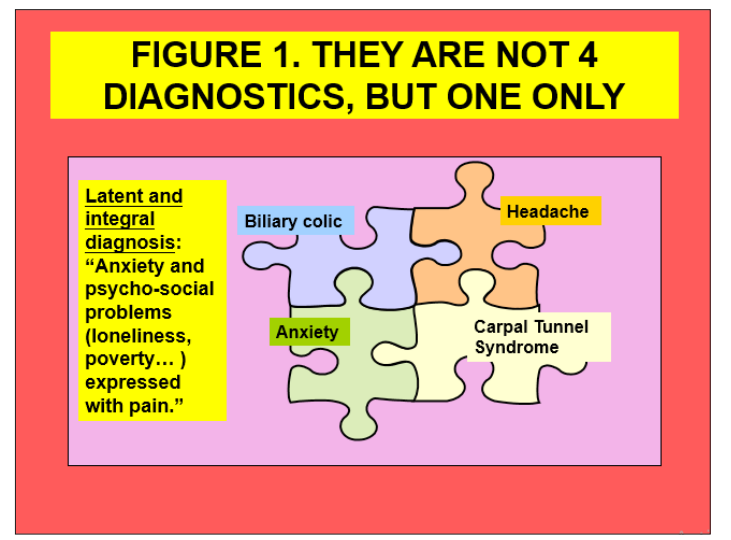

Figure 1: They are not 4 diagnostics, but one only.

The experience of the disease is different from the pathology classified by the doctor. It's like when we throw a stone into a calm pond; waves form on the surface of the water from the subjective experience of the person towards his family and friends, and depending on the intensity of the initial blow, they can also get to work, school, church ... And if the impact was big enough, or perhaps the pond small enough, the waves can hit the edges and overcome them which could cause a dysfunction in the body politic produced by the multiple waves of the initial blow, which no longer maintain their original elements. We call that a "disease [5].

Diagnosis means etymologically knowledge, but, global or partial knowledge? Traditionally, the diagnosis has focused on the physical complaint. The classic works of medicine describe meticulously, and sometimes disconnected, signs and symptoms of the patient. This model, which has hardly any evolutionary coherence in the natural history of the disease, can hardly promote the integration of the complaint in the true history of the patient. The patient has been isolated from his symptoms; to them, the professional has integrated them into a disease and usually returns them as impersonal information.

The course that adopts a disease and what it implies for the destiny of a man depends, not on the "disease", but, fundamentally on the patient, on his attitude towards life and his situation in it. Every sick person not only has his illness, but he himself and his destiny make his illness. Morbid history is always a biography [6].
The diagnosis occurs when the doctor chooses between a series of labels or classes. The main objectives of medical diagnostic classifications are still currently to predict the outcome, predict the response to specific treatments, and communicate the experience to others. In general medicine although the main classifications have chapters of general symptoms and social problems, the fundamental structure remains the disease located in organs and systems, expressed as diagnoses. The elements related to strengths, resources and potentials of the patients remain outside the classifications and diagnoses of general medicine despite their theoretical integral and positive vision of health.

In addition, diseases change over time, economic development, culture, environmental changes, and other factors. Thus, in the last 20 years important changes have occurred in infectious diseases, new diseases have appeared, others have disappeared, etc. So, epidemiological findings and scientific advances change and question the usefulness of diagnoses: the classification of peptic ulcer has been transformed from a psychosomatic to an infectious disease; The usefulness of distinguishing between common migraine and migraine diagnoses by muscle contraction is questionable, since these labels do not predict different results, etc. [7].

On the other hand, we must mention other characteristics of general medicine that modify the symptoms and diagnoses: There are problems instead of diseases; they are attended in the early stages of the disease/ problem; Symptoms and signs are often self-limiting; and symptomatology which is it seen in the hospital is different because of them are selected patients. So, although the diseases seen in the hospital and the general medicine are not the same, and these two work environments are not the same either (In hospital, patient attended is de-contextualized, emphasis is on the biological, technology and on the quantitative), clinical method has not differentiated. However, symptoms in general medicine and hospital are different and have its own specificities [8]. Experience has shown that diagnostic cataloguing is more a legal and administrative need than a therapeutic one. Nobody is a textbook patient: there is a tendency to make the diagnoses increasingly longer, richer, more complex and they move away more and more from the simple label; they should be more "integral and contextualized" in general medicine.

\section{References}

1. Turabián JL, Pérez Franco B (2011) The symptoms in family medicine are not symptoms of disease, they are symptoms of life. Aten Primaria 44(4): 232-236.

2. Turabian JL (2019) Interpretation of the reasons for consultation: manifest and latent content. the initiation of the diagnostic process in general medicine. Archives of Community and Family Medicine 2(1): $1-8$.

3. Hofmann B (2001) Complexity of the concept of disease as shown through rival theoretical frameworks. Theor Med Bioeth 22(3): 211-236.

4. WHO (2018) International statistical classification of diseases and related health problems?

5. De Barbaro B (2004) Between a psychiatric diagnosis and a familial diagnosis. Psychiatr Pol 38(5): 771-782. 
6. Siebeck R (1957) Medicine in motion. Scientific-Medical Editorial, Barcelona, USA.

7. Foucault M (1996) The birth of the clinic. An archeology of medical look. $21^{\text {st }}$ Century Editors, Mexico, USA, p. 272.
8. Turabian JL (1995) Notebooks of Family and Community Medicine. An introduction to the principles of Family Medicine. Diaz de Santos, Madrid, Spain.

For possible submissions Click below: 